\title{
Expedient Approach to the Synthesis of Betrixaban
}

\author{
Chada Raji Reddy ${ }^{* a, b}$ (D) \\ Sudam N. Sinare ${ }^{b}$ \\ ${ }^{a}$ Department of Organic Synthesis \& Process Chemistry, CSIR-Indian Institute \\ of Chemical Technology, Hyderabad-500007, India \\ rajireddy@iict.res.in \\ ${ }^{b}$ Academy of Scientific and Innovative Research (AcSIR), Ghaziabad 201 002, \\ India
}

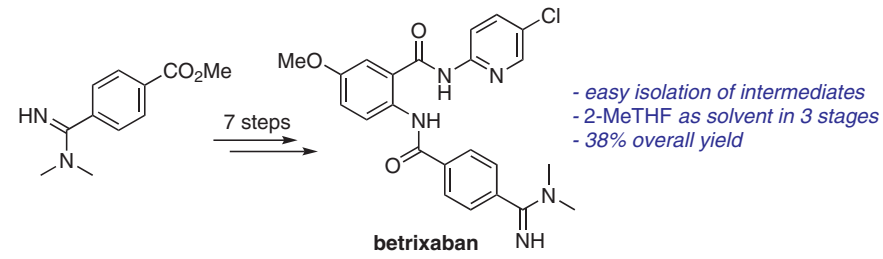

Due to the important activity of betrixaban in the prevention of venous thromboembolism (VTE), several strategies for its synthesis have been reported..$^{4,6-9}$ For example, the original approach by Kanter and co-workers (Scheme 1a) begins with the coupling of 5-methoxy-2-nitrobenzoic acid (2) with 2-amino-5-chloropyridine (3) in the presence of $\mathrm{POCl}_{3}$ and pyridine in acetonitrile to yield nitroamide $\mathbf{4}$, which, upon hydrogenation, provided the amino amide intermediate $\mathbf{5}$.
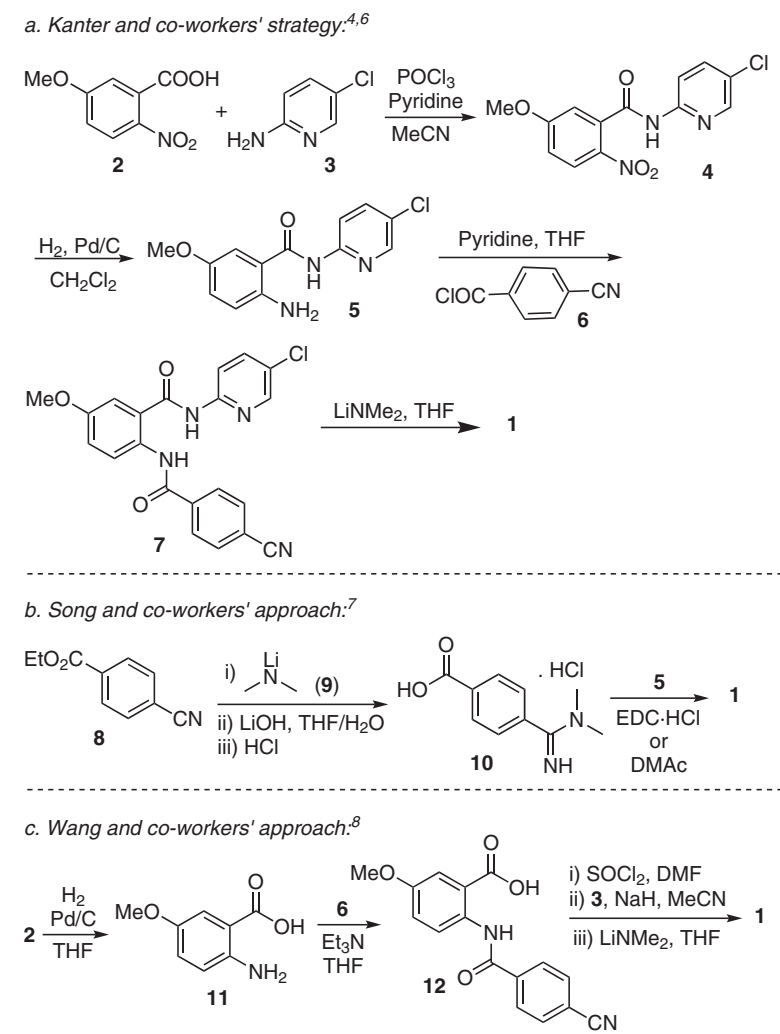

Scheme 1 Selected previous approaches to betrixaban (1)

Figure 1 Structure of betrixaban 
Treatment of 5 with 4-cyanobenzoyl chloride (6)/pyridine gave the cyano precursor $\mathbf{7}$, and reaction of the latter with lithium dimethylamide afforded the target molecule 1. ${ }^{4,6}$ Alternatively, a modified route has been developed by Song and co-workers (Scheme 1b), ${ }^{7}$ wherein the amidine $\mathbf{1 0}$ is prepared from the reaction of ethyl 4-cyanobenzoate (8) with lithium dimethylamide (9) followed by hydrolysis of the ester using lithium hydroxide in $\mathrm{THF} / \mathrm{H}_{2} \mathrm{O}$ and acidification with $\mathrm{HCl}$. Next, the coupling of amidine $\mathbf{1 0}$ with amino-amide $\mathbf{5}$, in the presence of $\mathrm{N}$-(3-dimethylaminopropyl)- $N$ '-ethylcarbodiimide hydrochloride (EDCl. $\mathrm{HCl}$ ) in DMF or dimethylacetamide, gave betrixaban (1). Later in 2015, Wang and co-workers reported a reaction sequence (Scheme 1c) starting from the reduction of 5-methoxy-2nitrobenzoic acid (2) to 2-amino-5-methoxybenzoic acid (11), ${ }^{8}$ wherein the dechlorination is avoided. Subsequently, the coupling of $\mathbf{1 1}$ with $\mathbf{6}$, in the presence of triethylamine, gave amidocarboxylic acid $\mathbf{1 2}$, which was subjected to amide formation with 2-amino-5-chloropyridine (3) to form the intermediate $\mathbf{7}$, followed by conversion of the cyano group into an amidine, leading to the target molecule $\mathbf{1}$. However, these routes suffer from one of the following drawbacks: (1) dechlorination during the reduction of the nitro group leads to an impurity that is difficult to separate; (2) the use of expensive coupling agents and/or (3) tedious workup procedures. These observations encouraged us to find an alternative approach to a scalable synthesis of betrixaban by circumventing the above disadvantages. In this direction, we planned the synthesis of betrixaban starting from $\mathrm{N}, \mathrm{N}$-dimethyl benziimididamide $\mathbf{1 3}$ in a protectected form for easy isolation of all the intermediates involving the late-stage coupling of 5-chloropyridin-2-amine (3).

In our strategy (Scheme 2), initially, methyl 4-(N,N-dimethylcarbamimidoyl)benzoate (13; prepared by following a reported procedure $)^{9}$ was protected as its tosylate by using tosyl chloride in the presence of triethylamine in 2methyltetrahydrofuran (2-MeTHF) ${ }^{10}$ Subsequent LiOH-mediated hydrolysis provided (E)-4-(N,N-dimethyl- $N^{\prime}$-tosylcarbamimidoyl)benzoic acid (14) in $85 \%$ yield. Coupling of acid 14 with commercially available methyl 2-amino-5-methoxybenzoate (15), in the presence of $\mathrm{POCl}_{3}$ in 2-MeTHF, afforded the corresponding amide ester, ${ }^{11}$ which, upon treatment with $\mathrm{LiOH}$ in water, delivered the amido-benzoic acid 16 in $81 \%$ yield. The amide formation of $\mathbf{1 6}$ with 5chloropyridin-2-amine (3) was carried out in a two-step sequence to avoid expensive coupling reagents.

Firstly, acid 16 was converted into benzoxazinone 17 using $\mathrm{POCl}_{3}, \mathrm{Et}_{3} \mathrm{~N} / \mathrm{DMAP}$ in 2-MeTHF in $82 \%$ yield. ${ }^{12}$ Then, DBU-promoted ring opening of $\mathbf{1 7}$ with amine $\mathbf{3}$ in toluene under reflux gave the tosyl-protected betrixabin $\mathbf{1 8}$ in $\mathbf{8 7 \%}$ yield. Finally, detosylation of $\mathbf{1 8}$ proceeded well with trifluoroacetic acid (TFA) ${ }^{13}$ in methanol to give betrixaban (1) in $78 \%$ yield. It is important to note that the use of 2-MeTHF

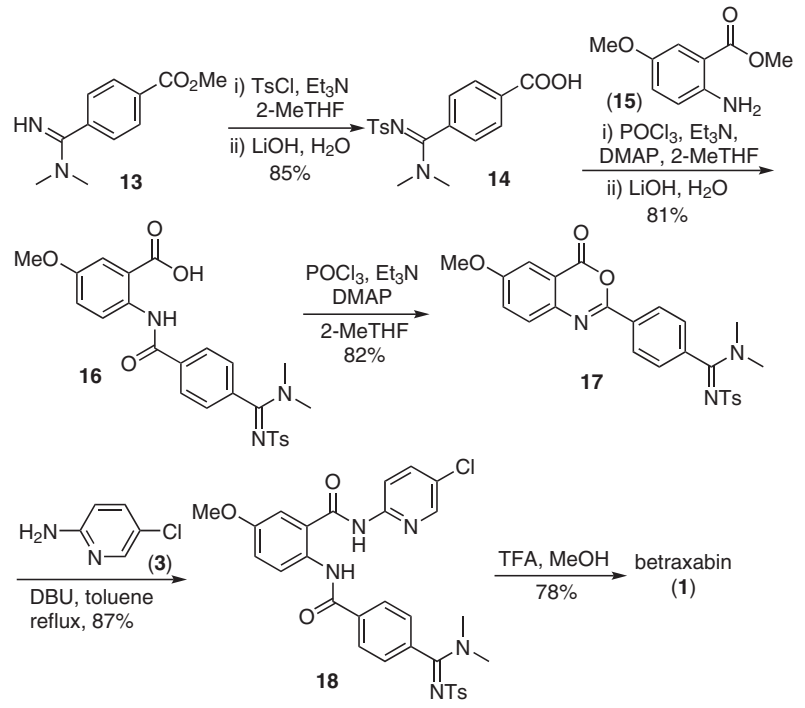

Scheme 2 Our approach to the synthesis of betrixaban (1)

(immiscible in water) as the solvent permits easy separation during the workup, and the organic layer containing the product can be directly used for the next reaction in the same solvent. Furthermore, this strategy avoids the requirement of additional solvent for extraction and isolation of intermediates in two stages.

A novel, convergent approach for the convenient and scalable synthesis of betrixaban has been developed by using methyl 4-(N,N-dimethylcarbamimidoyl)benzoate, methyl 2-amino-5-methoxybenzoate and 2-amino-5-chloropyridine as stating materials. The unique features of this sequence, including effective isolation of intermediates due to the presence of a tosyl group, use of cost-effective amide formation reactions, and 2-MeTHF as solvent medium for both the reaction and the extraction of the product in three steps, make this an attractive process. Furthermore, avoidance of nitro-group reduction and a late-stage Pinner reaction are added advantages to avoid the formation of the dechlorinated impurity and tedious work-up procedures (shortcomings in previous approaches). We believe that the developed approach is convenient for scale-up as well as for the synthesis for novel analogues.

All the starting materials, reagents and solvents were used as received without further purification, unless otherwise stated. Reactions were analysed by thin-layer chromatography (TLC) on silica and compounds were visualized with UV-light. ${ }^{1} \mathrm{H}$ NMR and ${ }^{13} \mathrm{C}$ NMR spectra were recorded with a $500 \mathrm{MHz}$ Agilent spectrometer in either $\mathrm{CDCl}_{3}$ or DMSO- $d_{6}$ with TMS as an internal standard. IR spectra were obtained with a Bruker-Alpha, Opus 8.2 spectrometer. Mass spectra were obtained with an AB SCIEX QTRAP 5500 LCMS/MS System. High-resolution mass spectra were recorded with either a TOF or double focusing spectrometer. 


\section{(E)-4-(N,N-Dimethyl- $N$ '-tosylcarbamimidoyl)benzoic Acid (14)}

To a mixture of methyl 4-(N,N-dimethylcarbamimidoyl)benzoate (13; $13 \mathrm{~g}, 0.063 \mathrm{~mol})$ and triethylamine (14.66 g, $0.145 \mathrm{~mol})$ in 2-Me THF $(130 \mathrm{~mL})$ under a nitrogen atmosphere was added tosyl chloride $(15.61 \mathrm{~g}, 0.082 \mathrm{~mol})$ dropwise at $10{ }^{\circ} \mathrm{C}$. Then, the mixture was allowed to warm to r.t. and stirred until completion $(2 \mathrm{~h}$, monitored by TLC). Upon completion, the mixture was cooled to $10{ }^{\circ} \mathrm{C}$, the reaction was quenched with water $(100 \mathrm{~mL})$, and the organic layer was washed with saturated aqueous sodium bicarbonate $(50 \mathrm{~mL})$. To the organic layer was added $\mathrm{LiOH}(1.73 \mathrm{~g}, 0.072 \mathrm{~mol})$ solution in water at $20{ }^{\circ} \mathrm{C}$ and the mixture was heated to $45^{\circ} \mathrm{C}$ for $8 \mathrm{~h}$. The reaction mixture was cooled to r.t. and diluted with water $(75 \mathrm{~mL})$, and the aqueous layer was cooled to $5^{\circ} \mathrm{C}$ and adjusted to $\mathrm{pH} 2.5$ by addition of $5 \mathrm{M} \mathrm{HCl}$ at $5{ }^{\circ} \mathrm{C}$. The precipitated solid was filtered, then dried at $50{ }^{\circ} \mathrm{C}$ to afford the desired acid 14.

Yield: $85 \%$ (18.56 g); $\mathrm{mp} 239-241{ }^{\circ} \mathrm{C}$.

${ }^{1} \mathrm{H}$ NMR $\left(500 \mathrm{MHz}\right.$, DMSO- $\left.d_{6}\right): \delta=13.09$ (br s, $\left.1 \mathrm{H}\right), 7.91(\mathrm{~d}, J=8.0 \mathrm{~Hz}$, $2 \mathrm{H}), 7.39$ (d, $J=8.0 \mathrm{~Hz}, 2 \mathrm{H}), 7.24(\mathrm{~d}, J=8.5 \mathrm{~Hz}, 1 \mathrm{H}), 7.20$ (d, $J=8.5 \mathrm{~Hz}$, $2 \mathrm{H}), 3.14(\mathrm{~s}, 3 \mathrm{H}), 2.71(\mathrm{~s}, 3 \mathrm{H}), 2.33(\mathrm{~s}, 3 \mathrm{H})$.

${ }^{13} \mathrm{C}$ NMR $\left(125 \mathrm{MHz}\right.$, DMSO- $\left.d_{6}\right): \delta=161.7,164.9,141.3,141.2,136.4$, $131.5,128.9,128.8,127.6,125.8,37.7,20.9$.

IR (neat): $3146,1715,1565,1218,1138,1077,878 \mathrm{~cm}^{-1}$.

MS (ESI): $m / z=347.2[\mathrm{M}+\mathrm{H}]^{+}$.

HRMS (ESI): $m / z$ [M $+\mathrm{H}]^{+}$calcd for $\mathrm{C}_{17} \mathrm{H}_{19} \mathrm{~N}_{2} \mathrm{O}_{4} \mathrm{~S}$ : 347.1066; found: 347.1069.

\section{(E)-2-(4-(N,N-Dimethyl- $N$ '-tosylcarbamimidoyl)benzamido)-5- methoxybenzoic Acid (16)}

To a mixture of acid 14 (16.5 g, $0.047 \mathrm{~mol})$, methyl 2-amino-5-methoxybenzoate $(\mathbf{1 5} ; 9.5 \mathrm{~g}, 0.052 \mathrm{~mol})$, triethylamine $(12.04 \mathrm{~g}, 0.119$ $\mathrm{mol}$ ) and 4-dimethylamino pyiridine $(1.75 \mathrm{~g}, 0.014 \mathrm{~mol})$ in 2-MeTHF $\left(165 \mathrm{~mL}\right.$ ) cooled to $5{ }^{\circ} \mathrm{C}$ under a nitrogen atmosphere was added phosphorus oxychloride $(8.76 \mathrm{~g}, 0.057 \mathrm{~mol})$ dropwise (slowly with care), then the mixture was stirred at r.t. for $2 \mathrm{~h}$. Upon completion, the mixture was cooled to $10{ }^{\circ} \mathrm{C}$ and diluted with water $(100 \mathrm{~mL})$. The organic layer was separated, washed with saturated aqueous sodium bicarbonate $(75 \mathrm{~mL})$ and taken on for hydrolysis. To the organic layer was added $\mathrm{LiOH}(1.31 \mathrm{~g}, 0.055 \mathrm{~mol})$ in water at $20^{\circ} \mathrm{C}$ and the reaction mixture was heated to $45^{\circ} \mathrm{C}$ until completion of reaction. The mixture was cooled to r.t., diluted with water $(30 \mathrm{~mL})$, and the aqueous layer was adjusted to $\mathrm{pH} 2.0$ by addition of $5 \mathrm{M} \mathrm{HCl}$ at $5{ }^{\circ} \mathrm{C}$. The precipitated solid was filtered and dried in vacuo at $50{ }^{\circ} \mathrm{C}$ to afford amidobenzoic acid 16.

Yield: 81\% (19.12 g); $\mathrm{mp} 266-268^{\circ} \mathrm{C}$.

${ }^{1} \mathrm{H}$ NMR (500 MHz, DMSO- $d_{6}$ ): $\delta=13.73$ (br s, $1 \mathrm{H}$ ), $11.82(\mathrm{~s}, 1 \mathrm{H}), 8.54$ $(\mathrm{d}, J=9.5 \mathrm{~Hz}, 1 \mathrm{H}), 7.90(\mathrm{~d}, J=8.5 \mathrm{~Hz}, 2 \mathrm{H}), 7.53(\mathrm{~d}, J=3.5 \mathrm{~Hz}, 1 \mathrm{H}), 7.39$ (d, $J=8.0 \mathrm{~Hz}, 2 \mathrm{H}), 7.32$ (d, $J=8.5 \mathrm{~Hz}, 2 \mathrm{H}), 7.29$ (dd, $J=9.0,3.0 \mathrm{~Hz}, 1$ H), $7.21(\mathrm{~d}, J=8.0 \mathrm{~Hz}, 2 \mathrm{H}), 3.81(\mathrm{~s}, 3 \mathrm{H}), 3.31(\mathrm{~s}, 3 \mathrm{H}), 2.74(\mathrm{~s}, 3 \mathrm{H}), 2.34$ (s, $3 \mathrm{H})$.

${ }^{13} \mathrm{C}$ NMR $\left(125 \mathrm{MHz}\right.$, DMSO- $\left.d_{6}\right): \delta=169.3,164.9,163.6,154.6,141.4$, $141.1,135.5,135.3,134.0,128.9,127.9,126.5,125.8,122.2,120.1$, $118.8,115.0,55.4,37.7,20.9$.

IR (neat): 3275, 1699, 1604, 1542, 1218, 1145, 851, $674 \mathrm{~cm}^{-1}$.

MS (ESI): $m / z=496.15[\mathrm{M}+\mathrm{H}]^{+}$.

HRMS (ESI): $m / z[M+H]^{+}$calcd for $\mathrm{C}_{25} \mathrm{H}_{26} \mathrm{~N}_{3} \mathrm{O}_{6} \mathrm{~S}: 496.1542$; found: 496.1545.
(E)-4-(6-Methoxy-4-oxo-4H-benzo[d][1,3]oxazin-2-yl)- N,N-dimethyl- $\boldsymbol{N}$-tosylbenzimidamide (17)

To a mixture of acid $\mathbf{1 6}(17.5 \mathrm{~g}, 0.035 \mathrm{~mol}), \mathrm{Et}_{3} \mathrm{~N}(8.92 \mathrm{~g}, 0.088 \mathrm{~mol})$ and DMAP $(1.29 \mathrm{~g}, 0.011 \mathrm{~mol})$ in 2-MeTHF $(175 \mathrm{~mL})$ was added dropwise phosphorus oxychloride $(6.5 \mathrm{~g}, 0.042 \mathrm{~mol})$ under a nitrogen atmosphere at $5{ }^{\circ} \mathrm{C}$ (slowly with care), then the reaction mixture was stirred at r.t. for $5 \mathrm{~h}$. The mixture was cooled to $10{ }^{\circ} \mathrm{C}$, diluted with water $(100 \mathrm{~mL})$, and the organic layer was washed with saturated aqueous sodium bicarbonate $(75 \mathrm{~mL})$ and brine $(50 \mathrm{~mL})$. The organic layer was concentrated in vacuo below $50{ }^{\circ} \mathrm{C}$ to give the crude benzoxazinone 17 which was used further without any purification.

Yield: $82 \%$ (13.83 g); $\mathrm{mp} 217-219{ }^{\circ} \mathrm{C}$.

${ }^{1} \mathrm{H} \mathrm{NMR}\left(500 \mathrm{MHz}\right.$, DMSO- $\left.d_{6}\right): \delta=8.13(\mathrm{~d}, J=8.0 \mathrm{~Hz}, 2 \mathrm{H}), 7.71(\mathrm{~d}, J=$ $8.5 \mathrm{~Hz}, 1 \mathrm{H}), 7.59$ (d, $J=8.0 \mathrm{~Hz}, 2 \mathrm{H}), 7.42(\mathrm{~d}, J=8.5 \mathrm{~Hz}, 2 \mathrm{H}), 7.34$ (d, $J=8.0 \mathrm{~Hz}, 2 \mathrm{H}), 7.23(\mathrm{~d}, J=8.5 \mathrm{~Hz}, 2 \mathrm{H}), 3.92(\mathrm{~s}, 3 \mathrm{H}), 3.16(\mathrm{~s}, 3 \mathrm{H}), 2.75$ (s, $3 \mathrm{H}), 2.34$ (s, $3 \mathrm{H})$.

${ }^{13} \mathrm{C}$ NMR $\left(125 \mathrm{MHz}\right.$, DMSO- $\left.d_{6}\right): \delta=164.8,159.1,158.7,153.8,141.3$, $141.2,140.1,135.8,131.0,128.9,128.7,128.0,127.0,125.8,125.3$, $117.9,109.0,56.0,37.7,20.9$.

IR (neat): 3023, 1748, 1551, 1517, 1259, 1085, 870, $665 \mathrm{~cm}^{-1}$. $\operatorname{MS}(\mathrm{ESI}): m / z=478.1[\mathrm{M}+\mathrm{H}]^{+}$.

HRMS (ESI): $m / z$ [M + H] $]^{+}$calcd for for $\mathrm{C}_{25} \mathrm{H}_{24} \mathrm{~N}_{3} \mathrm{O}_{5} \mathrm{~S}: 478.1437$; found: 478.1442 .

(Z)-N-(5-Chloropyridin-2-yl)-2-(4-( $N, N$-dimethyl- $N$ '-tosylcarbamimidoyl)benzamido)-5-methoxybenzamide (18)

To a stirred solution of benzoxazinone $\mathbf{1 7}(12 \mathrm{~g}, 0.025 \mathrm{~mol})$ in toluene (72 mL) under a nitrogen atmosphere, was added 2-amino-5-chloropyridine 3 ( $4.19 \mathrm{~g}, 0.033 \mathrm{~mol}$ ) and the mixture stirred for $12 \mathrm{~h}$ under reflux. Upon completion, the reaction mixture was cooled to r.t., filtered, and the solid was dried under vacuum to afford tosylated betrixaban 18.

Yield: $87 \%$ (13.25 g); $\mathrm{mp} 236-238^{\circ} \mathrm{C}$.

${ }^{1} \mathrm{H}$ NMR $\left(500 \mathrm{MHz}\right.$, DMSO- $\left.d_{6}\right): \delta=11.09(\mathrm{br} \mathrm{s}, 2 \mathrm{H}), 8.43(\mathrm{~d}, J=3.0 \mathrm{~Hz}$, $1 \mathrm{H}), 8.16(\mathrm{~d}, J=8.5 \mathrm{~Hz}, 1 \mathrm{H}), 8.05(\mathrm{~d}, J=9.0 \mathrm{~Hz}, 1 \mathrm{H}), 7.95$ (dd, $J=9.0$, $3.0 \mathrm{~Hz}, 1 \mathrm{H}), 7.87(\mathrm{~d}, J=8.5 \mathrm{~Hz}, 2 \mathrm{H}), 7.44(\mathrm{~d}, J=3.0 \mathrm{~Hz}, 1 \mathrm{H}), 7.38(\mathrm{~d}$, $J=8.0 \mathrm{~Hz}, 2 \mathrm{H}$ ), 7.27 (d, J = 8.5 Hz, $2 \mathrm{H}$ ), 7.19 (d, $J=7.0 \mathrm{~Hz}, 3 \mathrm{H}), 3.85$ (s, $3 \mathrm{H}), 3.14(\mathrm{~s}, 3 \mathrm{H}), 2.72(\mathrm{~s}, 3 \mathrm{H}), 2.28(\mathrm{~s}, 3 \mathrm{H})$.

${ }^{13} \mathrm{C}$ NMR $\left(125 \mathrm{MHz}\right.$, DMSO- $\left.d_{6}\right): \delta=167.2,165.0,164.1,155.3,150.7$, $146.3,141.3,141.2,137.8,135.3,130.7,128.9,127.7,126.8,126.3$, $125.8,125.4,124.6,118.1,116.3,113.8,55.5,37.7,20.8$

IR (neat): 3269, 1661, 1573, 1372, 1142, 1086, 879, $667 \mathrm{~cm}^{-1}$. MS (ESI): $m / z=606.2[\mathrm{M}]^{+}$.

HRMS (ESI): $m / z[M]^{+}$calcd for $\mathrm{C}_{30} \mathrm{H}_{28} \mathrm{ClN}_{5} \mathrm{O}_{5} \mathrm{~S}$ : 606.1572; found: 606.1584 .

\section{Betrixaban (1) $)^{4,8}$}

To a solution of tosyl betrixaban $\mathbf{1 8}(12.00 \mathrm{~g}, 0.02 \mathrm{~mol})$ in $\mathrm{MeOH}$ (90 $\mathrm{mL}$ ) under a nitrogen atmosphere, was added trifluoroacetic acid $(6.81 \mathrm{~g}, 0.060 \mathrm{~mol})$ at $5{ }^{\circ} \mathrm{C}$ and the mixture stirred for $12 \mathrm{~h}$ at r.t.. To the white precipitate was added a solution of sodium bicarbonate $(8.35 \mathrm{~g}, 0.099 \mathrm{~mol})$ in water $(900 \mathrm{~mL})$. The reaction mixture was stirred for $30 \mathrm{~min}$, filtered, and the wet solid was taken into 2-MeTHF $(120 \mathrm{~mL})$. The resultant slurry was heated to reflux $\left(80^{\circ} \mathrm{C}\right)$ for $2 \mathrm{~h}$, then cooled to r.t., filtered, and the solid was dried under vacuum to afford betrixaban (1).

Yield: 78\% (6.98 g); $\mathrm{mp} 215-216.5^{\circ} \mathrm{C}$. 
${ }^{1} \mathrm{H}$ NMR (500 MHz, DMSO- $d_{6}$ ): $\delta=11.13(\mathrm{~s}, 1 \mathrm{H}), 11.07$ (s, $\left.1 \mathrm{H}\right), 9.49$ (s, $1 \mathrm{H}), 9.37$ (s, $1 \mathrm{H}), 8.27$ (d, J = 2.0 Hz, $1 \mathrm{H}), 8.10$ (d, J = 9.0 Hz, $1 \mathrm{H}), 8.08$ $(\mathrm{d}, J=8.5 \mathrm{~Hz}, 2 \mathrm{H}), 7.96(\mathrm{~m}, 2 \mathrm{H}), 7.74(\mathrm{~d}, J=8.5 \mathrm{~Hz}, 2 \mathrm{H}), 7.42(\mathrm{~d}, J=3.0$ $\mathrm{Hz}, 1 \mathrm{H}), 7.18$ (dd, J = 9.0, 3.0 Hz, 1 H), 3.85 (s, $3 \mathrm{H}$ ), 3.27 (s, $3 \mathrm{H}), 2.97$ (s, $3 \mathrm{H})$.

${ }^{13} \mathrm{C}$ NMR (125 MHz, DMSO- $\left.d_{6}\right): \delta=167.1,163.9,163.8,155.6,150.5$, 146.3, 137.8, 137.4, 132.2, 130.2, 128.6, 127.7, 126.8, 125.8, 124.9, $118.1,116.2,113.8,55.5,41.8$.

IR (neat): 3382-2945, 1649, 1607, 1212, 1178, 846, $690 \mathrm{~cm}^{-1}$. MS (ESI): $m / z=452.4[\mathrm{M}+\mathrm{H}]^{+}$.

\section{Funding Information}

C.R.R. is grateful to the Council of Scientific and Industrial Research (CSIR), New Delhi for financial support as part of mission mode project (INPROTICS; HCP 011).

\section{Acknowledgement}

SN.S. thanks Cipla Ltd., Mumbai for supporting doctoral research as part of a collaborative project with CSIR-IICT, Hyderabad. CSIR-IICT Communication No. IICT/Pubs./2020/221.

\section{Supporting Information}

Supporting information for this article is available online at https://doi.org/10.1055/s-0040-1707267.

\section{References}

(1) Eriksson, B. I.; Quinlan, D. J.; Weitz, J. I. Clin. Pharmacokinet. 2009, 48,1 .

(2) Turpie, A. G. G.; Bauce, K. A.; Davidson, B. L.; Fisher, W. D.; Gent, M.; Huo, M. H.; Sinha, U.; Gretler, D. D. Thromb. Haemost. 2009, 101, 68.

(3) Palladino, M.; Merli, G.; Thomson, L. Expert Opin. Invest. Drugs 2013, 22, 1465.

(4) Zhang, P.; Huang, W.; Wang, L.; Bao, L.; Jia, Z. J.; Bauer, S. M.; Goldman, E. A.; Probst, G. D.; Song, Y.; Su, T.; Fan, J.; Wu, Y.; Li, W.; Woolfrey, J.; Sinha, U.; Wong, P. W.; Edwards, S. T.; Arfsten, A. E.; Clizbe, L. A.; Kanter, J.; Pandey, A.; Park, G.; Hutchaleelaha, A.; Lambing, J. L.; Hollenbach, S. J.; Scarborough, R. M.; Zhu, B.-Y. Bioorg. Med. Chem. Lett. 2009, 19, 2179.

(5) Huisman, M. V.; Klok, F. A. Eur. Heart J. Suppl. 2018, 20, E12.

(6) Kanter, J. P.; Suizno, K.; Zuberi, S. S. PCT Int. Appl. WO2008057972, 2008

(7) Pandey, A.; Leitao, E. P. T.; Rato, J.; Song, Z. J. PCT application WO 2011084519, 2011

(8) Li, J.; Chen, L.; Yan, X.; Li, Y.; Wei, D.; Wang, D. J. Chem. Res. 2015, 39, 524.

(9) Pinto, D. J.; Qiao, J. X.; Gangor, T.; Lam, P. Y. S.; Li, Y.-L. PCT Int. Appl. WO2004083174, 2004; A2 20040930, 2004

(10) Bailey, C.; Baker, E.; Hayler, J.; Kane, P. Tetrahedron Lett. 1999, 40, 4847.

(11) Chen, H.; Xu, X.; Liu, L.; Tang, G.; Zhao, Y. RSC Adv. 2013, 3 , 16247.

(12) Errede, L. A.; McBrady, J. J. J. Org. Chem. 1977, 42, 3863.

(13) (a) Li, J.; Mi, Y.; He, J.; Luo, X.; Fan, E. J. Heterocycl. Chem. 2013, 50, 304. (b) Javorskis, T.; Orentas, E. J. Org. Chem. 2017, 82, 13423. 